\title{
Kenya: Training can enhance providers' management of FGM/C and willingness to advocate against the practice
}

Population Council

Follow this and additional works at: https://knowledgecommons.popcouncil.org/departments_sbsr-rh

Part of the Demography, Population, and Ecology Commons, Family, Life Course, and Society Commons, Gender and Sexuality Commons, International Public Health Commons, Medicine and Health Commons, Sociology of Culture Commons, and the Women's Health Commons How does access to this work benefit you? Let us know!

\section{Recommended Citation}

"Kenya: Training can enhance providers' management of $\mathrm{FGM} / \mathrm{C}$ and willingness to advocate against the practice," FRONTIERS OR Summary. Washington, DC: Population Council, 2008. 


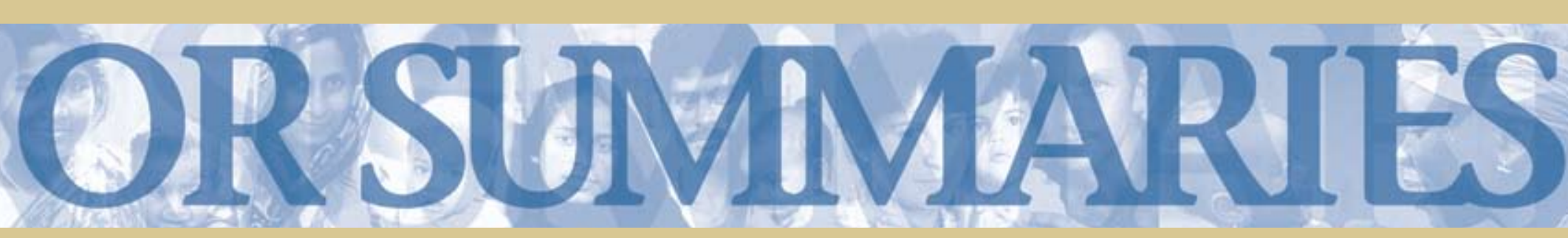

\section{Kenya \\ FGM/C}

OR Summary 71

\section{Training Can Enhance Providers' Management of FGM/C and Willingness to Advocate Against the Practice}

Following attendance at training workshops on managing pregnant women with FGM/C, health providers in Kenya's North Eastern Province showed increased knowledge and improved skills. They developed action plans for integrating the skills learned and for advocacy and community education on FGM/C. The curriculum has been adopted by the Kenyan government. Training for other providers serving excised women has begun.

\section{Background}

In 2004 FRONTIERS collaborated with UNICEF on a study on the cultural basis of female genital mutilation/cutting (FGM/C) in Kenya's Somali community and on ways of managing maternal care for cut women. Most Somali women are infibulated, meaning that their external genitalia have been removed and joined together with a small aperture left for the passage of urine - a condition shown by the World Health Organization to be associated with increased incidence and severity of childbirth complications, relative to uncut or less severely cut women. ${ }^{1}$ The study showed that the under-resourced health care system in North Eastern Province, where many Somalis live, is ill prepared to deal with women who have been cut, particularly infibulated women who are pregnant or delivering. The study recommended improving providers' ability to counsel and treat pregnant cut women as part of an overall improvement of maternal care, and strengthening providers' role as behavior change agents within communities.

In 2005 the FRONTIERS Program launched an intervention, in collaboration with the Kenyan Ministry of Health (MOH), UNICEF, and DANI$\mathrm{DA}$, to test an intervention to address medical complications of FGM/C in the Somali community. The strategy was to train health care providers in North Eastern Province to better manage

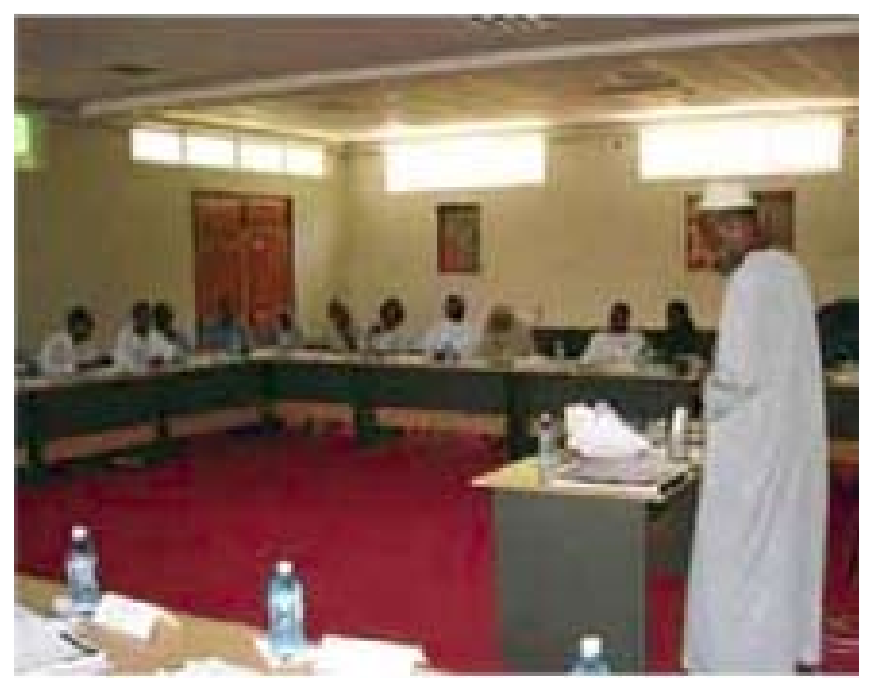

A religious leader clarifies Islam's view on FGM/C in an interactive session, showing that the practice not required and actually violates some Islamic views.

pregnant women, and to build their readiness to advocate against the practice of FGM/C with their clients and within their communities. The training was carried out at Garissa Provincial General Hospital, a medical center of excellence in Kenya and a referral center for North Eastern Province.

Five seven-day training sessions took place, conducted by a cadre of master trainers from the seven participating districts, and were attended by a total of 145 health workers (mainly nurses and midwives, but also medical and public health officers, providers from refugee hospitals, and hospital administrators, among others) from all 
facilities in the province. Participants received theoretical and practical training on managing antenatal care and delivery with reference to caring for women with FGM/C; imams made presentations on the cultural perspectives, and MOH managers emphasized the ministry's perspective. Training materials were based on a manual developed by the Population Council and approved by the $\mathrm{MOH}$. All participants were also trained in advocating against FGM/C in their clinical practice.

Changes in knowledge were measured through pre- and post-training tests. Trainees developed an action plan for improving the quality of care at their facilities.

\section{Results}

- The training sessions significantly increased participants' knowledge. Average scores for each participating district increased by about 11 to 20 percentage points, achieving post-test scores from a low of 76 to a high of 87 .

- Action plans (from a sample of 22 participants from all districts) focused on strengthening specific services, enhancing supervision, and increasing community outreach. Participants' priority actions included improving infection prevention, updating staff on reproductive health, maternal care, and $\mathrm{FGM} / \mathrm{C}$, increasing supportive supervision, talking with clients and the community on FGM/C and general health, and setting up emergency trays.

- Responding to requests for more practical experience, trainers conducted a four-day practical training course in the provincial hospital in Garissa. Fifteen providers attended classes and practiced their skills in antenatal and delivery counseling, care, and deinfibulation for women with $\mathrm{FGM} / \mathrm{C}$.

- Workshop participants' suggestions included providing the course at the district level, following up at clinics to ensure that providers are using their knowledge, and integrating sessions with community and religious leaders to help diffuse information to communities.

\section{Utilization}

- The manual developed by the Population Council, Management of complications, pregnancy, childbirth and the postpartum period in the presence of Female Genital Cutting/Mutilation: Manual for Health Workers, was adopted by the Ministry of Health as a national document.

\section{Next Steps}

- The Population Council is now collaborating with other groups working in North Eastern and neighboring provinces to sustain the knowledge gained during the training. With support from the Canadian International Development Agency, the Council is integrating FGM/C into the provincial strategy to prevent and manage violence against women.

- With the UNHCR and GTZ, the Population Council has used this experience to strengthen health services for Somali and Ethiopian refugees receiving pregnancy care in Nairobi.

January 2008

Kenya Ministry of Health. 2008. "Reproductive health update trainings for health workers in North Eastern Province, Garissa," Ministry of Health/Population Council report. Nairobi: MOH/Population Council. Available on our website at www.popcouncil.org/frontiers or by e-mail: frontiers@popcouncil.org

This publication is made possible by the generous support of the American people through the United States Agency for International Development (USAID) under the terms of Cooperative Agreement No. HRN-A-00-98-00012-00. The contents are the responsibility of the FRONTIERS Program and do not necessarily reflect the views of USAID or the United States Government. 